\title{
Why does Aotearoa New Zealand need an Osteoarthritis Summit?
}

In July this year, at the University of Auckland, a steering committee for the newly formed initiative 'Osteoarthritis Aotearoa New Zealand' hosted a gathering we called the 'Taupuni Hao Huatau Kaikōiwi Osteoarthritis Basecamp'. This one-day event included national and international presenters and attendees from across the spectrum of healthcare, from a broad range of clinical practitioners to health funders to researchers. The cause that drew people to the event was a desire to see better management for people living with osteoarthritis (OA) in Aotearoa New Zealand. During the event, we undertook two workshops to prioritise OA care delivery and research. One message that came through very clearly from these workshops is that people want cohesion in the organisation and delivery of healthcare for people with OA. A finding supported by previous papers calling for the implementation of a Model of Care to guide service delivery for OA in Aotearoa New Zealand (Baldwin et al., 2017; O'Brien et al., 2021).

The purpose of the Aotearoa New Zealand Osteoarthritis Summit initiative is to facilitate strategic planning for a national response to the growing burden of OA and to galvanise action to address this burden. It takes inspiration from the successful series of Osteoarthritis Summits in Australia, led by the prominent rheumatologist and world-leading OA expert Professor David Hunter (Hunter et al., 2019). The kaupapa aims to connect the OA research and innovative health delivery community, foster increased collaboration in OA research and innovative health delivery in Aotearoa New Zealand, and facilitate a cohesive approach to OA research and innovative health delivery in Aotearoa New Zealand from basic science to translational research and implementation by forming an OA research network and facilitating interdisciplinary and inter-institutional collaboration. The fundamental objectives of the kaupapa in Aotearoa New Zealand are to (1) co-create a National Model of Care for OA and (2) develop a list of national priorities in OA research and innovative health delivery.

Clinical services must be collaborative and responsive to the needs of all New Zealanders with OA. In a paper within this issue of the Journal (Dixon et al., 2021), we explore the experiences of living with OA for ngā tāne Māori (Māori men) and discuss some strategies to improve engagement. While this paper focuses on the experiences of ngā tāne Māori, some of the lessons learnt could have a broader impact. For example, we could examine the importance of whakawhanaungatanga, the value of relationship building with your patient (or community) so you can better serve their needs. We are hopeful that this notion of understanding the community's needs will underpin the Ministry of Health's development of the new Regional Networks and Māori Health Authority as part of the planned health reform in 2022. Furthermore, Dixon et al. (2021) highlight how research can inform clinical practice.
Physiotherapists have an essential role to play in the management of OA in Aotearoa New Zealand. It is a role that spans the complete spectrum of care, ranging from sports injury prevention programmes for our youth to physical activity promotion, traumatic injury rehabilitation, early symptom management, and pre- and post-operative rehabilitation. Furthermore, physiotherapists are well placed to contribute to research in all these areas and more. We had great professional engagement from physiotherapists at the Basecamp event and hope to have even greater representation at the Aotearoa New Zealand Osteoarthritis Summit in July 2022. For anyone interested in being involved in this kaupapa, you can go to the summit website: https://events.otago.ac.nz/2021-osteoarthritisbasecamp/wellington-summit

\section{Daniel W. O'Brien PhD}

Senior Lecturer, Department of Physiotherapy; Active Living and Rehabilitation: Aotearoa New Zealand, Health and Rehabilitation Research Institute, School of Clinical Sciences, Auckland University of Technology, Auckland, New Zealand.

Email: daniel.obrien@aut.ac.nz

\section{J. Haxby Abbott $P h D, F N Z C P$}

Professor, Department of Surgical Sciences; Director of the Centre for Musculoskeletal Outcomes Research, University of Otago, Dunedin, New Zealand.

Email: haxby.abbott@otago.ac.nz

https://doi.org/10.15619/NZJP/49.3.01

\section{REFERENCES}

Baldwin, J., Briggs, A. M., Bagg, W., \& Larmer, P. J. (2017). An osteoarthritis model of care should be a national priority for New Zealand. New Zealand Medical Journal, 130(1467), 78-86.

Dixon, T.-W., O'Brien, D., Terry, G., Baldwin, J. N., Ruakere, T., Mekkelholt, T., \& Larmer P. J. (2021). The lived experiences of Māori tāne with hip and knee osteoarthritis. New Zealand Journal of Physiotherapy, 49(3), 127-133. https://doi.org/10.15619/NZJP/49.3.03

Hunter, D. J., Nicolson, P. J. A., Little, C. B., Robbins, S. R., Wang, X., \& Bennell, K. L. (2019). Developing strategic priorities in osteoarthritis research: Proceedings and recommendations arising from the 2017 Australian Osteoarthritis Summit. BMC Musculoskeletal Disorders, 20, 74 https://doi.org/10.1186/s12891-019-2455-x

O’Brien, D. W., Pigg, W., Ellis, R., Baldwin, J. N., Quicke, J. G., Evans, N., \& Dziedzic, K. S. (2021). An evidence-informed model of care for people with lower limb osteoarthritis in New Zealand. New Zealand Journal of Physiotherapy, 49(1), 24-30. https://doi.org/10.15619/NZJP/49.1.04 